is chairman of the management committee of the Low Temperature Station for Research in Biochemistry and Biophysics at Cambridge. Our fuel supplies are ample; our food supplies come from all over the world, and the successful preservation and carriage of fruit, vegetables, meat, and fish affect every home. The storage of fruit has been studied for ten years, and it is proposed to publish a comprehensive report on it. Special attention has been given to apples, and recent investigations show that there is a critical low temperature for each variety of apple, below which the fruit rapidly deteriorates in storage. For the study of fruit an experimental station is being erected at East Malling, and for the study of fish a research laboratory is being inaugurated at Aberdeen. Towards the cost of these the Empire Marketing Board is assisting. The value of the fish landed in Great Britain last year was $£ 18,000,000$; the value of the meat imported, $£ 109,000,000$ - figures which indicate the importance of the trade in these commodities.

While many of the inquiries led to long and difficult experiments in the laboratory, an example of work of more immediate practical application arose through requests made by the Sheffield and Leicester Corporations. The question was whether the hanging of meat improved its palatability. Experiments were made with meat conditioned at $32^{\circ} \mathrm{F}$. and $41^{\circ} \mathrm{F}$. up to ten days hanging, and it was found that the palatability was improved, the flavour was retained, and the texture and juiciness of the meat improved. In the tests, assistance was received from members of King's College for Women and the staff of Messrs. J. Lyons and Co.
Houses, furniture, and clothing are as necessary as food and fuel, and the work of the Building Research Board, the Forest Products Research Board, and that done by the Cotton, Woollen, Silk, Leather, Boot and Shoe, and other Research Associations, afford many examples of the value of the scientific method applied to age-long problems. Limes, plasters, cements, paints, breeze, artificial stone, the weathering of stone, the vibration of buildings, wind pressure on structures, are being investigated by the Building Research Board, while the Forest Products Research Board is dealing with the anatomical structure of woods; the seasoning of furniture timbers, the shrinkage and deterioration of timbers, the testing of pit props, and the habits of the various insects which destroy our roofs and furniture. Many firms apply to the Boards for information, and, in addition to advisory work at home, much has been undertaken for places so far apart as Burma, British Honduras, Australasia, and Kenya.

In other directions work is proceeding on metals and alloys, boiler plates and ingot steel, corrosion, the fatigue of metals, electro-deposition, springs, radio telegraphy and telephony, lubrication, castiron, refractories, and many engineering problems. While one department is engaged on the study of steel, another is considering the advisability of establishing a national locomotive experimental station, and yet another is doing work of value for our cathedrals and churches. Canada, Australia, New Zealand, South Africa, and India are all following in the footsteps of the Mother Country : they all have research organisations, and of their activities the report gives a brief review.

\title{
A New High Voltage Research Laboratory.
}

THE opening by Sir Ernest Rutherford of the 1 high voltage research laboratory of Metropolitan-Vickers Electrical Co., Ltd., at Trafford Park, Manchester, on Feb. 28 is a noteworthy event. The increasing use of the outdoor type of construction for high voltage apparatus makes it necessary to determine how this apparatus will act during gales, thunderstorms, and snow-storms. As the standard pressure for distributing electrical energy in Great Britain is 132,000 volts, and a factor of safety of three or four is desirable, it is very advisable that all devices for use in high voltage lines should be tested at pressures of several hundred thousand volts.

In the present state of our knowledge, the performance of insulating material under very high pressures can in general only be determined by experiment. Although there are now several laboratories abroad which have facilities for testing at a million volts with a large reserve of power, yet with the exception of the high voltage equipment at the National Physical Laboratory, Teddington, there was none in England. It is highly satisfactory, therefore, that one of the largest industrial firms should have built a million volt laboratory under the supervision of its able engineers.
The present laboratory consists of two semiindependent main buildings and an annex. The smaller of the two main buildings, which is $47 \mathrm{ft}$. long by $67 \mathrm{ft}$. broad, was built in 1923 as a 500,000 volt-power frequency laboratory. When it was decided to extend the equipment to give a million volts, the second main building, $67 \mathrm{ft}$. by $86 \mathrm{ft}$., was laid down with a wall in common with the original building. The latter is now equipped with devices for producing transient voltages and is called the 'surge' laboratory. The annex contains the materials and physics laboratories and a machine room where all the generators and running machinery are isolated so as to reduce noise.

The main electrical equipment consists of two 500,000 volt, 500 k.v.a., 50 cycle transformers, one being located in the main laboratory and the other in the surge laboratory. For producing a million volts, the two transformers are connected in cascade by the well-known Dessauer method. The second transformer, the one in the main laboratory, is shown in Fig. 1. As the primary winding of this transformer has a potential difference to earth of 500,000 volts, the whole transformer has to be thoroughly insulated from the earth. This is done by means of pedestal pillars which support the tank 
containing the transformer. The two transformers are practically identical in construction, each being of the core type with each limb wound. They are both immersed in oil.

The accurate measurement of high voltages is a problem of considerable difficulty. The standard method is to use two spherical electrodes ; then, if their potentials are equal and opposite at the instant of the discharge, the potential difference between them can be computed with an accuracy of about one per cent, provided that there are no brush discharges taking place in the neighbourhood. When one of the electrodes is earthed, the accuracy obtainable is not so high, possibly because the potential of the 'earthed' sphere is not zero.

The method adopted in the new laboratory at Trafford Park depends on the theorem that the average charging eurrent of a condenser is proportional to its capacity and to the maximum value of the voltage. Hence when the capacity and frequency are known and the average current due to the voltage is measured, the maximum voltage can be deduced. A meter is so arranged that its reading gives the voltage directly. The condenser employed consists of large surfaces, each twenty feet in diameter and having air between them (see Fig. 1). The surfaces employed are flattened and symmetrical about a vertical axis. One is supported directly on the bushing insulator of the high voltage transformer, and the other is suspended immediately above it from the roof. This condenser is the largest high-voltage condenser yet constructed.

The power rating of each of the transformers is 500 kilovoltamperes, so that very large currents can be supplied at the instant of spark-over. In order to get satisfactory results, it is well known that it is necessary to have a large amount of reserve power available. The control of the generators which are housed in the machine room is done from the control desks in the laboratories. Push buttons control the starting and stopping of the driving motors, the rheostats which govern their speed and the frequency meters. 'The potentiometer regulators which control the voltage are motor-driven and give a uniform rate of voltage variation over the entire range with the motor running at constant speed.

The photograph of a power frequency arc at a pressure of 970,000 volts is shown in Fig. 2. The spark gap is $12 \mathrm{ft}$. The man shown in the illustration was not present when the arc occurred; if he had been he probably would have been killed. $\mathrm{He}$ is merely included in the photograph to indicate the scale of the phenomenon ; this was done by a double exposure. On first entering the laboratory, one is impressed by the large amount of floor space which is apparently not utilised. Remembering, how-

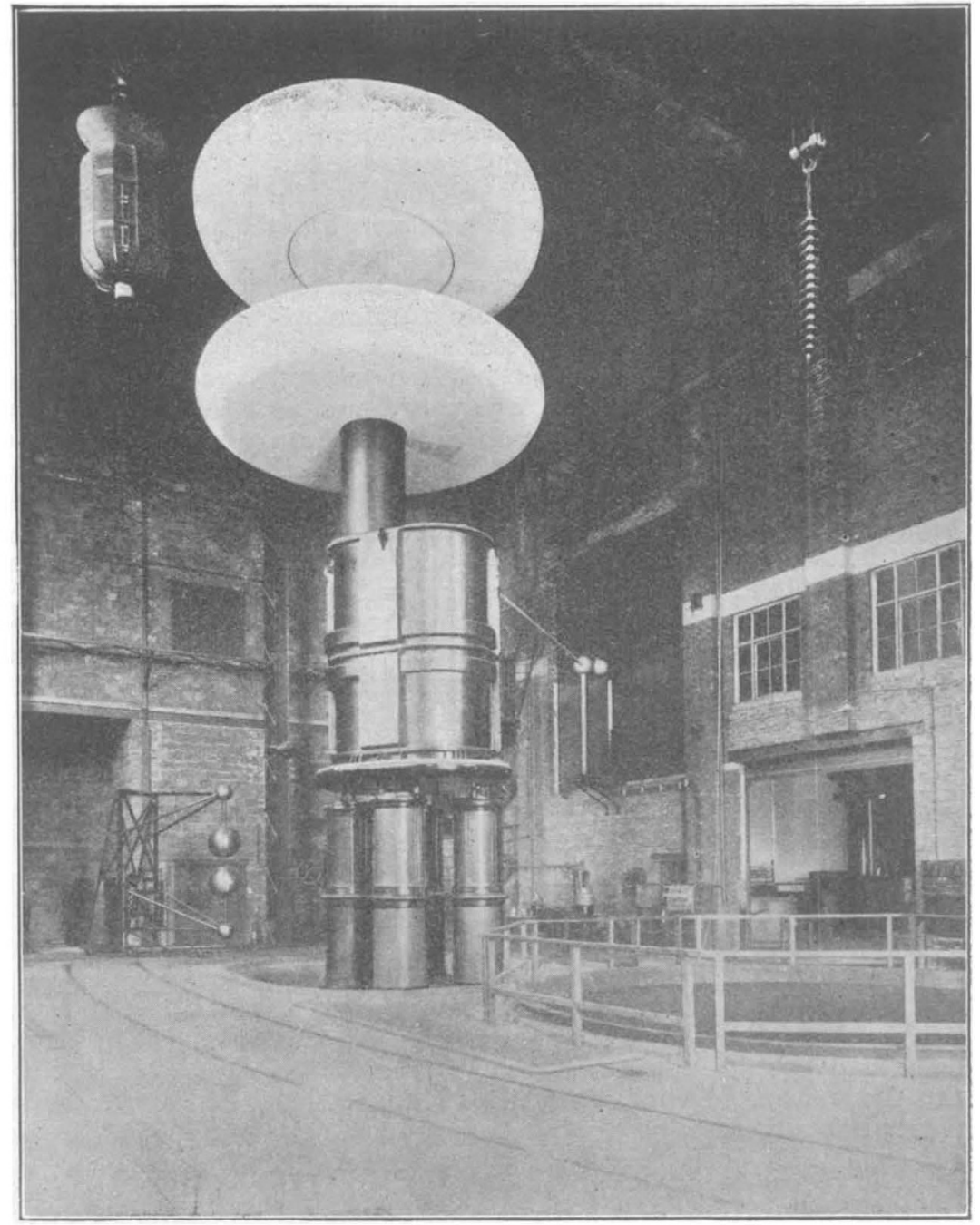

FIG. 1.-Interior view of the main High Voltage Laboratory at Trafford Park.

No. 3149 , VoL. 125]

ever, that at a million volts 12 -ft. arcs can occur, it will be seen that any material or apparatus being tested must be at least that distance away from walls and objects connected with the earth. Taking the dimensions of the transformer into account, it was found that a clear space at least $30 \mathrm{ft}$. in diameter was absolutely necessary.

In order to make full scale tests of large porcelain insulators immersed in oil, it was found advisable to make a tank 25 feet in diameter and 10 feet in depth. This has a volume of about 4000 cubic $\mathrm{ft}$. and would contain about 20,000 gallons of oil. Good insulating oil is not cheap, so this must repre- 
sent quite a large amount of capital. The necessity also of keeping it dry and clean must add considerably to the cost. It will be seen that these million voltage tests must be very expensive. The majority of the tests will be carried out by the two transformers used individually at 500,000 volts or less. In the materials laboratory there are three transformers producing voltages of $11,000,22,000$, and 100,000 for ordinary tests. Two tanks are pro. vided, for making tests in hot and cold oil. There are four testing chambers in the middle of the room, where the materials can be tested at various temperatures and humidities.

In the surge laboratory (Fig, 3), apparatus j.s provided for testing devices and materials when subjected to transient voltages produced in various ways. In systems used for transmitting electrical power, three kinds of surges are recognised: first, those caused by a sudden variation of the load or the 'runaway' of a generator; secondly, those due to high frequency surges of internal origin caused by switching or by an arcing fault; and thirdly, the surges caused by atmospheric disturbances, including lightning discharges. Modern operating experience in Great Britain where the reutral is earthed indicates that lightning is the only source of overvoltage that has to be guarded asainst. 'The design of the insulators, therefore, must be such that the minimaum amount of damage is done when the lightning arc-over occurs. The dangerous transients are the "impulsive rushes" which were described fully and experimentally demonstrated by Sir Oliver Lodge so long ago as 1889 (Jour. Inst. Elect. Engin., yol. 18, p. 386; 1889).

By arranging a condenser so that it is suddenly discharged when a spark gap flashes over, it is easy to get what Lodge called an impulsive rush. By arranging a series of them in parallel, we can construct an impulse generator. The generator in the surge laboratory can produce transient voltages up to $1,500,000$. A mechanical rectifier is installed which produces a voltage of about 700,000 . This is mainly used for operating the impulse generator. Another set equipped with thermionic rectifiers is generally employed for direct current voltage tests. Its maximum voltage is 250,000 volts, and its terminals can either be at equal and oppositc voltages or one of them may be earthed.

A special Schering bridge has been constructed for measuring dielectric losses at pressures up to 500,000 volts. Electro-mechanical tests on porcelain insulators, and design studies on switch-gear and transformor parts, have frequently to be carried out in this laboratory. It is one of the best equipped laboratories in the world, and Messrs. MetropolitanVickers Electrical Co., Ltd, , are to be congratulated on having recognised always that it is nocessary to use the best and most scientific methods of testing the materials they use in manufacturing their machines and devices and for detcrmining their factors of safety.

In declaring the laboratory open, Sir Ernest Rutherford expressed the hope that before long we may be able, by using millions of rolts, to produce copious streams of high velocity atoms and electrons in the laboratory. An abundant supply of swift particles would open up many new avenues of attack on the fundamental problems

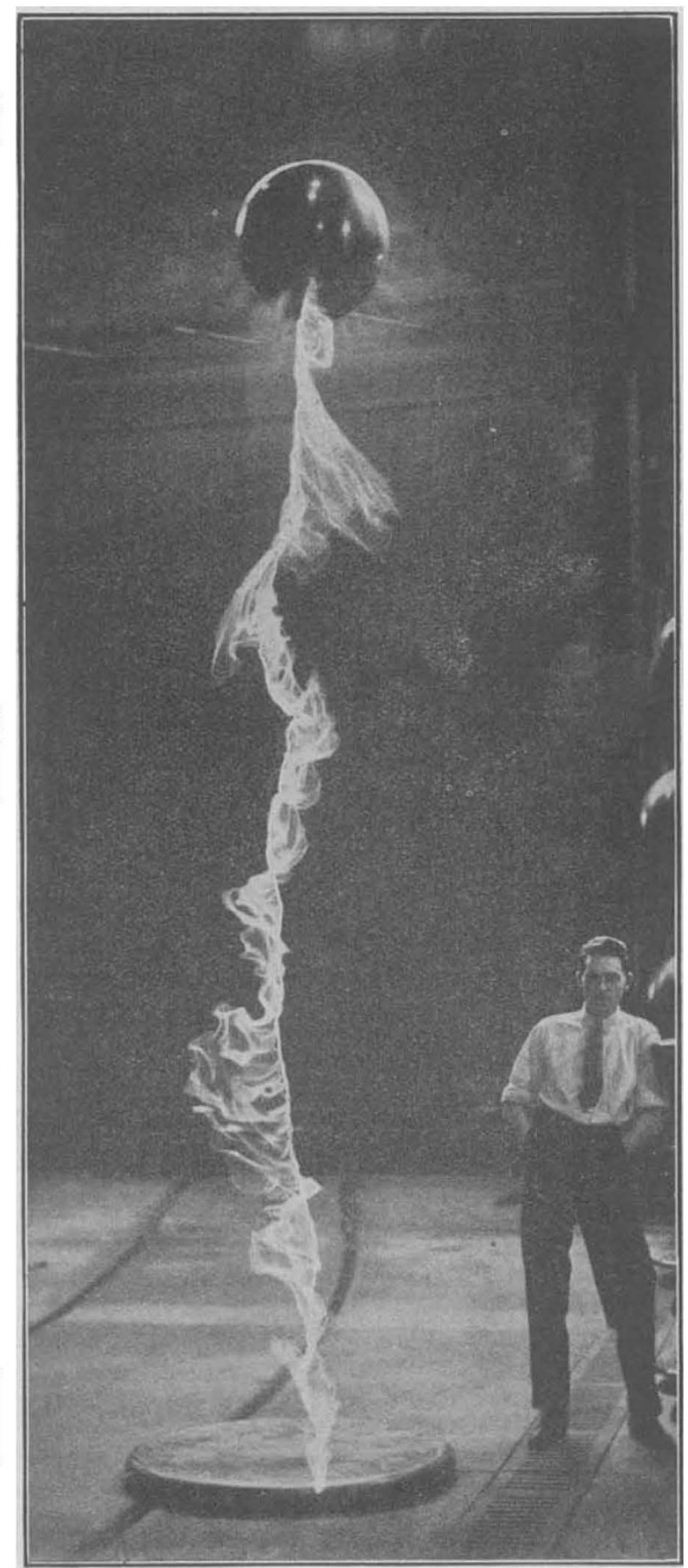

Fra. 2. - Fower frequency are at a pressure of 970,000 volts in a 12 -ft gap. The man was photographed Beparately.

of physics. Unfortunately, the finances of the ordinary university laboratory are very limited. It is too much for a university to hope for a laboratory like this one approaching a eathedral in size. It is possible, however, that an apparatus may be devised which can be operated by a small

No. 3149, VoL. 125] 
transformer in an ordinary-sized room giving ten that the design of such a device does not offer million kilovolts to a vacuum tube. Such a piece / insuperable difficulties. He congratulated the

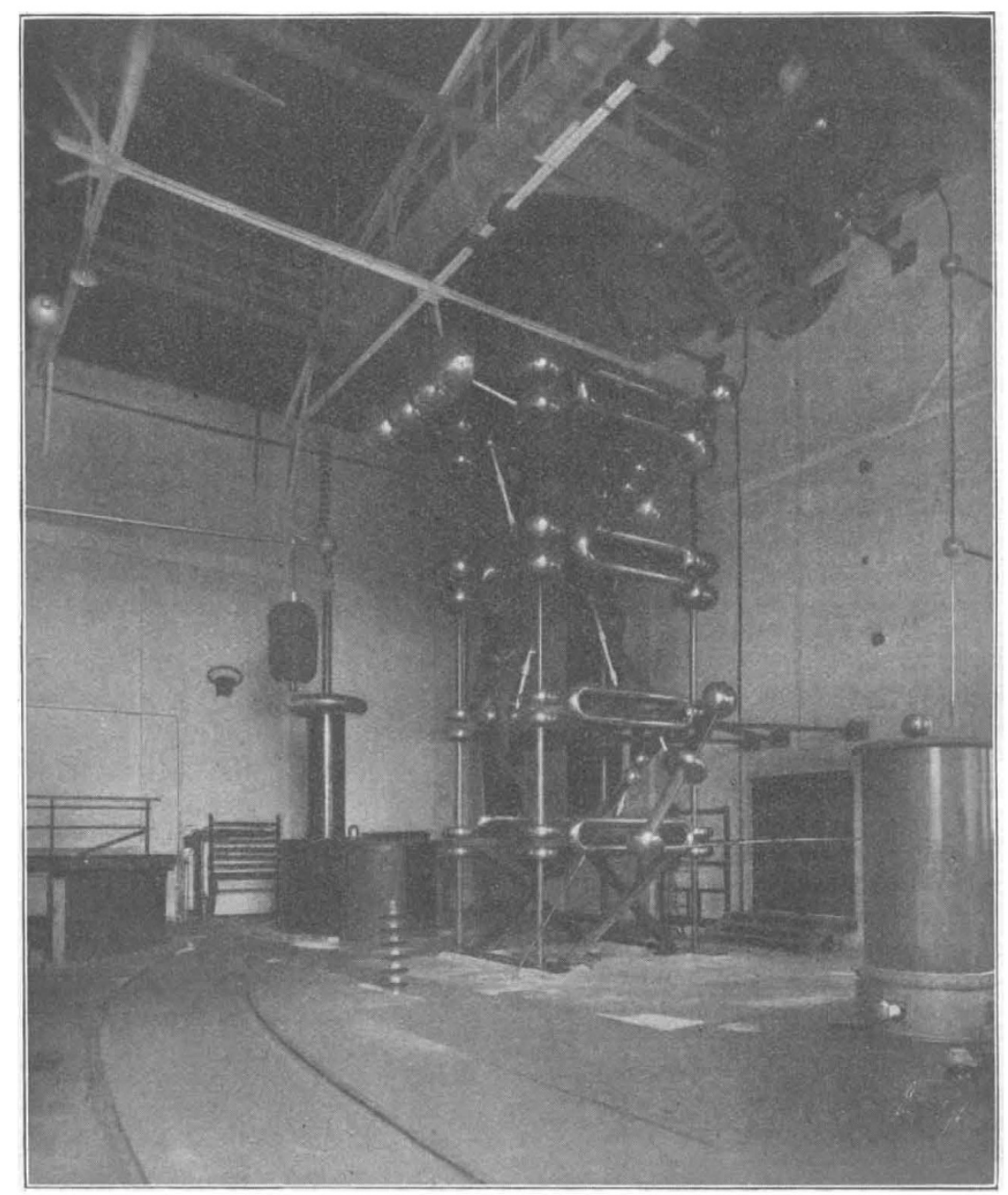

FIG. 3.-Impulse generator in Surge Laboratory.

of apparatus would be a great help in physical research ; and considering the great progress made by engineers in recent years, Sir Ernest believes
Metropolitan-Vickers Electrical Co., Ltd., and its research department on its far-sighted policy in initiating high voltage research.

\section{Obituary.}

Mr. A. A. Campbell Swinton, F.R.S.

BY the death of Alan Archibald Campbell 1 Swinton on Feb. 19, scientific research loses one who has done valuable work especially in $\mathrm{X}$-rays and radio communication. The third son of Archibald Campbell Swinton of Kimmerghame, Berwickshire, he was born on Oct. 18, 1863. His father was a professor of civil law in the University of Edinburgh from 1842 to 1862 and was also Brigadier-General in the Royal Company of Archers. He could prove direct descent from the
Royal House of Scotland. Prof. Swinton's second son was Captain George S. C. Swinton, who was chairman of the London County Council in 1912 and chairman of the town-planning committee of the new city of Delhi. He was also Lord Lyon King of Arms. Prof. Swinton's sister was the mother of Archbishop Lord Davidson.

When a child, Alan Campbell Swinton showed a bent towards engineering. An oil painting of him when aged nine, with a steam-engine in his hand, was shown at the Royal Scottish Academy (Continued on p. 385.)

No. 3149, Vol. 125] 